\title{
THE USE OF 3D VIRTUAL LEARNING ENVIRONMENTS IN TRAINING FOREIGN LANGUAGE PRE-SERVICE TEACHERS
}

\author{
Dr. Tuncer CAN \\ Dept. of English Language Teaching \\ Hasan Ali Yucel Faculty of Education \\ Istanbul University, Istanbul, TURKEY \\ Dr. Irfan SIMSEK \\ Dept. of Computer Education and Instructional Technologies, \\ Hasan Ali Yucel Faculty of Education \\ Istanbul University, Istanbul, TURKEY
}

\section{ABSTRACT}

The recent developments in computer and Internet technologies and in three dimensional modelling necessitates the new approaches and methods in the education field and brings new opportunities to the higher education. The Internet and virtual learning environments have changed the learning opportunities by diversifying the learning options not only in general education but also in the field of foreign language for teachers, curriculum designers and students. Many higher education institutions are employing one of the most widely used virtual worlds the Second Life Platform and are conducting classes on their virtual campuses, and organize meetings, seminars and conferences. In this study, it has been aimed to devise and implement learning applications on the 3D Second Life Platform for the prospective foreign language preservice teachers of Istanbul University, Hasan Ali Yücel Faculty of Education, English Language Teaching Department. The study will report a research Project on Second Life aiming at introducing foreign language pre-service teachers with 3D Virtual Learning Environments and enabling them to use this environment for language teaching at Istanbul University, Hasan Ali Yucel Faculty of Education, English Language Teaching Department. In the scope of the Project, "Comparative Education" class has been conducted both face to face and in World. The method of the study is descriptive. Furthermore, a mixed model, where qualitative and quantitative research techniques have analyzed, has been used. Thus, triangulation of the data has been aimed. In the study, a description of the project, methodology, results and student work will be given.

Keywords: Three dimensional virtual learning environments, foreign language teacher training, technology teacher training, distance education.

\section{INTRODUCTION}

The 3-D virtual learning environments (VLE) could be classified as an application of computer assisted language learning (CALL). According to Kluge and Riley, (2008, p. 128) these VLEs are regarded as "multi-user virtual environments (MUVE) or Metaverse". To Warburton (2009, p. 414) the most popular 3-D multi-user virtual environment is the Second Life (SL) (http://secondlife.com/). Since the start-up of SL more than 36 millions of people have opened accounts and have joined the virtual worlds. 3D VLEs are "computer-generated display that allows or compels the user (or users) to have a sense of being present in an environment other than the one they are actually in, and to interact with that environment" (Schroeder, 1996, p. 25 in Warburton, 2009, p. 415). Edirisingha, 
Nie, Pluciennik and Young (2009, p. 459) persist that "a 3-D MUVE, such as SL, has the potential to generate a sense of presence among peer learners via their avatars in a 3-D environment through real-time interactions that may facilitate relationship-building, learners' engagement and motivation".

The learners could be present in the environment by creating a new identity in the form of an avatar (Ushioda, 2011, p. 207). The form, shape and appearance of the avatar could be chosen, developed and changed by the learners themselves, and thus the learning experience could be individualized (Salmon, 2009, p. 526). As anonymous avatars, learners could attend to the learning environment, which as a result decreases the stress and anxiety and raises learners' motivation (Chang, 2005, Ushioda 2011). Consequently, the learners take more risks and attend to activities more actively; these in return support foreign language learning (Peterson, 2010, s. 274). SL platform is a "student centered virtual learning platform" (Coffman \& Klinger, 2008, p. 30) as it supports and varies the opportunities for learners to choose the content independently while designing the learning environment.

Second Life, enables its avatars to use body language to some extend and eases the use of voice chat and thus supports the communication and interaction among the avatars, from which language education and distance learning applications could also benefit. Eventually, the real World in which humans actually use body language and voice is also modelled (Salmon, 2009, p. 529). With this real time synchronous communication and interaction leaners could come together, make groups, learn in cooperation and socialize (Edirisingha et al. 2009, p. 459). SL is an environment where learning by role playing, experiential learning, cooperative learning and game based learning (Warburton, 2010, p. 421, Salmon, 2009, p. 528), authentic learning and meaningful learning (Keskitalo, Pyykkö and Roukamo, 2011, s. 17), constructivist learning (Kluge and Riley, 2008, p. 127; Can 2009, p. 63), task based learning (Peterson, 2010) could be realized.

This 3-D VLE is constructed, owned, changed and developed by the "content and objects that are created by the learners" (Keskitalo et al. 2011, Salmon 2009, p. 532). Learners have the freedom to design the learning environment itself. They can design and construct the environment in collaboration by determining scenarios, own what they create and construct the knowledge by free will. In this respect, learners could relate to their own content, objects and other fellow learners, which enable them to be more active and independent in the learning process (Kluge \& Riley, 2008). Thus, learners could attend to autonomy by having opportunity to decide on the design, objects, knowledge and what they create in the learning process. Learners are immersed in such environments that cater for realistic feeling of presence and opportunity of interaction (Salmon, 2009, Warburton, 2009, Keskitalo et al. 2011).

Kluge and Riley (2008) distinguish between challenges for students and educators. They believe "robust hardware and a broad band Internet connection, liability issues like being subjected to sex, violence, or disruptive players" are the biggest challenges for students who want to participate to classes in virtual classes. Apart from technical issues like bandwidth problems a number of educators might not have the skills to create and design the learning environment. Cost is another challenge in front of the educators, and many of the features of the Learning Management Systems, like reporting the amount of time spent in the virtual world or storing the grades earned and homeworks to be reviewed later, do not exist (pp. 131-132).

Warburton (2009) reports a survey of newsgroups, blog posts and the extant literature from Warburton \& Perez-Garcia, (2009, pp. 422-423) where they discovered eight broad categories of issues: 1) Technical, 2) Identity, 3) Culture, 4) Collaboration, 5) Time, 6) Economic, 7) Standards, 8) Scaffolding persistence and social discovery.(pp. 422-423) 
$>$ Technical issues are either computer related like bandwidth, hardware and firewalls or server issues like down time and lag, or use-related issues like navigation, creating objects, manipulating one's avatar.

> Identity issues like freedom to play with identity and manage reputation can become an issue of concern, and accountability for actions becomes displaced.

$>$ Culture issues like set of codes, norms and etiquette for joining communities.

$>$ Collaboration issues like the need of building trust and authenticity while cooperating and co-construction and because of a minimal social network scheme within the virtual learning environments, external services such as wikis, blogs or a virtual learning environment (VLE) are often needed to support the interactions between avatars.

$>$ Time constraints could occur by validating, running and teaching activities. Checking object permissions, intellectual property rights and accessibility also requires a lot of time.

$>$ Economic issues; even though the basic account to access Second Life is free, anything else costs money like buying land to build and create teaching spaces or uploading images and textures.

$>$ Standardization presently is a problem. There is no interoperability between various virtual platforms, yet.

$>$ Scaffolding persistence and social discovery issues like each avatar remains trapped at the center of its own community and in-world profiles associated with each avatar provide a limited mechanism for the social discovery of other people, unlike other social networking services.

\section{THE STUDY}

The Aim of the Study

There are very few studies that look into the use of 3D VLEs for teacher education, training and development, let alone foreign language teachers. Some European Union projects a have attempted to do so. For instance, AVALON Project $(2009 / 2011)$ aimed at "creating and piloting a training course for teachers who would like to extend their teaching skills to include working in virtual worlds". Another Project looking at this field is ASSIS (2011) funded by Umea University in Sweden. The Project "makes use of the affordances offered by Second Life in order to raise sociolinguistic language awareness among teacher trainees and other students studying courses in sociolinguistics". (Deutschmann \& Steinvall, 2011).

The AVATAR Project (2009/2011) supported by European Union "provides an opportunity for both teachers and students to benefit from ICT skill development, social learning opportunities and a resource to help revive the traditional classroom environment, adding value to the learning process". Another European Union Project "Euroversity Project" $(2011 / 2014)$ tries to find out ways to bring together teachers, professionals and institutions across Europe to use modern VLEs and contribute to the modern language education.

The recent European Union "CAMELOT Project" (2013/2015) also targets language teachers by providing teacher training course to equip teachers with 21st century digital skills necessary to record machinima and create their own ad hoc materials in 3D VLEs. The field was investigated for example studies from Turkey, and one such study was observed from Middle East Technical University as part of MA study in Computer and Instructional Technologies Department and students were asked about their opinions about the SL. 
With these in mind, our project specifically aims at using 3D Virtual Learning Environments in Training Foreign Language Pre-Service Teachers. For this, in 2012 we applied to Istanbul University Scientific Research and Projects Center and secured a grant to be able to introduce Istanbul University Hasan Ali Yücel Faculty of Education, English Language Teaching Department senior students, the pre-service language teachers with 3D Virtual Learning Environments and enable them to use this environment for language teaching.

With the grant a station computer, to conduct the lessons, and place on Second life was rented. The SL location was Plot 12 on Edunation III. This place was selected deliberately on the potential it had for education as it is hosting universities, like Free University of Berlin and Dublin University, from around Europe in November 2012. The teacher of the class and technical staff was made acquainted with he environment first and teacher and the technical staff of the project collaborated in designing the classroom for the students. The Computer lab of Faculty was secured for those students who might want to join but have no access facilities on their own. Couple of Project meetings were done on the plot to gather experience and observe the possible problems and solutions.

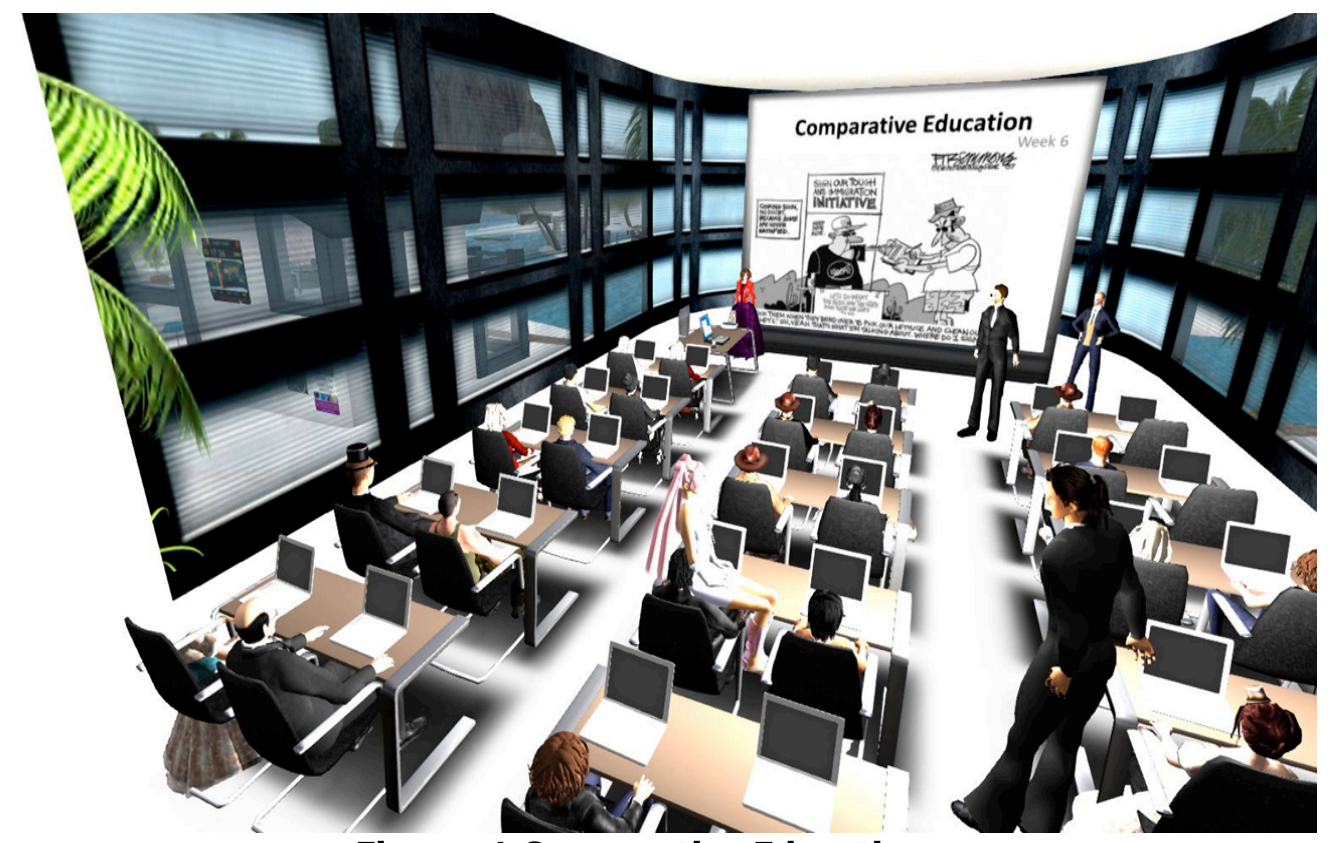

Figure: 1 Comparative Education.

Then, in the spring term of 2013 «Comparative Education» lesson was chosen as the field of application. The class was hold two times a week, face to face on Tuesdays regularly, and when students were invited for online synchronous lesson on the plot, they asked for a Friday evening class. After the agreement the lessons on SL started a week later but caught up the order of the face to face lesson on the mid-term weeks, as there are no face to face classes during this period.

Before the classes started learners were given pre-test about readiness for online/distance learning and inflict the idea of 3D VLEs. Lessons were conducted for 10 weeks during this semester.

The Project was disseminated to the University circles and on social media, designed a website www.iusanalkampus.com and Facebook group https://www.facebook.com/ IstanbulUniversityVirtualCampus, and a channel on youtube http://www.youtube.com /secondlifeiu/ and an account on twitter https://twitter.com/IUSecondLife. 
After the lessons, a Post test was applied on our Facebook group and Interview questions were submitted on Moodle that asked about the experience of our students on SL.

\section{METHOD}

The method of the study is descriptive. Furthermore, a mixed model, where qualitative and quantitative research techniques have been analyzed, has been used. Thus, triangulation of the data has been aimed.

The study group comprises of Istanbul University Hasan Ali Yücel Faculty of Education English Language Teaching Department Senior students. Before the study learners were given pre-test about readiness for online/distance learning and inflict the idea of 3D VLEs.

After the completion of the class the pre-service teachers were given a questionnaire asking for their opinion about the experience in the virtual world and open-ended questions to reflect on their experience. 36 English Language Teaching Department Students and participated in the initial test, 16 Female and 10 male students answered the Interview questions.

\section{FINDINGS}

$\% 96$ of the students who contributed to the research have stated that they own a computer and \%95 of those have asserted having Internet access in their homes or dorms. The frequency tables regarding the items of the questionnaire have been given.

Table: 1

Findings regarding item :

"How much were you able to control events?"

\begin{tabular}{lcc}
\hline & $\mathbf{f}$ & $\mathbf{\%}$ \\
\hline Never & $\mathbf{0}$ & $\mathbf{0 \%}$ \\
Rarely & $\mathbf{5}$ & $\mathbf{1 4 \%}$ \\
Sometimes & $\mathbf{3}$ & $\mathbf{7 \%}$ \\
Often & $\mathbf{2 6}$ & $\mathbf{7 1 \%}$ \\
Always & $\mathbf{3}$ & $\mathbf{7 \%}$ \\
\hline
\end{tabular}

When Table 1 is examined, it has been observed that only \%14 of the students have stated having problems controlling the events in the environment, the rest has been observed to be having no problems. However, when students were asked (How responsive was the environment to actions that you initiated (or performed)?) $\% 79$ answered as often, and \%14 have answered as always.

Table: 2

Findings regarding item:

How natural did your interactions with the environment seem?"

\begin{tabular}{lcc}
\hline & f & $\%$ \\
\hline Never & 0 & $0 \%$ \\
Rarely & 3 & $7 \%$ \\
Sometimes & 5 & $14 \%$ \\
Often & 28 & $79 \%$ \\
Always & 0 & $0 \%$ \\
\hline
\end{tabular}

As seen in Table 2 the majority of the students persist that their interactions with the environment seems natural. 
Table: 3

Findings regarding item:

"How completely were all of your senses engaged?"

\begin{tabular}{lcc}
\hline & f & $\%$ \\
\hline Never & 0 & $0 \%$ \\
Rarely & 0 & $0 \%$ \\
Sometimes & 5 & $14 \%$ \\
Often & 26 & $71 \%$ \\
Always & 5 & $14 \%$ \\
\hline
\end{tabular}

According to Table 3, it has been observed that students senses are pretty engaged. Also $\% 64$ of the students expressed that the visual aspects of the environment often and \%21 always involves them.

Table: 4

Findings regarding item:

"How compelling was your sense of objects moving through space?"

\begin{tabular}{lll}
\hline & f & $\%$ \\
\hline Never & 0 & $0 \%$ \\
Rarely & 15 & $43 \%$ \\
Sometimes & 18 & $50 \%$ \\
Often & 3 & $7 \%$ \\
Always & 0 & $0 \%$ \\
\hline
\end{tabular}

Big majority of the participants in the research have put forward that the sense of objects moving through space was not compelling. However, \%50 have declared that the information coming from variety of senses is compelling.

Table: 5

Findings regarding item:

"How much did your experiences in the virtual environment seem consistent with your real-world experiences?"

\begin{tabular}{lcc}
\hline & f & $\%$ \\
\hline Never & 0 & $0 \%$ \\
Rarely & 3 & $7 \%$ \\
Sometimes & 5 & $14 \%$ \\
Often & 23 & $64 \%$ \\
Always & 5 & $14 \%$ \\
\hline
\end{tabular}

As could be seen in Table $5 . \% 78$ of the participants have verbalized that the "experiences in the virtual environment seem consistent with their real-world experiences" as often and always.

$\% 64$ of the Participants have asserted that sounds coming from outside the environment are significant,

$\% 85$ that they could actively examine and research the environment by using the visuals, and $\% 79$ that they could search the virtual environment actively by touching. 
Table: 6

Findings regarding item:

"How well could you move or manipulate objects in the virtual environment?"

\begin{tabular}{lcc}
\hline & f & $\%$ \\
\hline Never & 5 & $14 \%$ \\
Rarely & 10 & $29 \%$ \\
Sometimes & 18 & $50 \%$ \\
Often & 3 & $7 \%$ \\
Always & 0 & $0 \%$ \\
\hline
\end{tabular}

Table: 7

Findings regarding item:

"How involved were you in the virtual environment experience?"

\begin{tabular}{lll}
\hline & $\mathbf{f}$ & $\%$ \\
\hline Never & 0 & $0 \%$ \\
Rarely & 0 & $0 \%$ \\
Sometimes & 8 & $21 \%$ \\
Often & 15 & $43 \%$ \\
Always & 13 & $36 \%$ \\
\hline
\end{tabular}

As it could be understood from table 7. Big majority of the participants have been involved in the virtual environment experience.

Table: 8

Findings regarding item:

"How proficient in moving and interacting with the virtual environment did you feel at the end of the experience?"

\begin{tabular}{lcc}
\hline & f & $\%$ \\
\hline Never & 0 & $0 \%$ \\
Rarely & 3 & $7 \%$ \\
Sometimes & 8 & $21 \%$ \\
Often & 26 & $71 \%$ \\
Always & 0 & $0 \%$ \\
\hline
\end{tabular}

$\% 71$ of the participants have felt proficient in moving and interacting with the virtual environment at the end of the experience.

Table: 9

Findings regarding item:

How well could you concentrate on the assigned tasks or required activities rather than on the mechanisms used to perform those tasks or activities?"

\begin{tabular}{lcc}
\hline & f & $\%$ \\
\hline Never & 0 & $0 \%$ \\
Rarely & 0 & $0 \%$ \\
Sometimes & 13 & $36 \%$ \\
Often & 21 & $57 \%$ \\
Always & 3 & $7 \%$ \\
\hline
\end{tabular}

$\% 36$ of the Learners have put forward that they "sometimes" could concentrate on the assigned tasks or required activities rather than on the mechanisms used to perform 
those tasks or activities, $\% 57$ often and $\% 7$ always. They (\%64) also asserted that they learnt new techniques that could alter their performance.

The answers given to the semi-structured interview form are as follows:

What was the most interesting experince you had in SL?

«Flying.»

«First time I couldn't find my class, I got angry at myself.»

«Writing a notecard during the class to our teacher.»

«Having our rector so close, speaking to us astonished me.»

«Meeting my former Erasmus friends in SL was great.»

«A friend of mine who has never spoken to me in the class face to face asked me a question in SL for help, this was very interesting to me.»

«While strolling around a person offered me a cigarette like in real life.»

What was difficult in SL?

«Controlling my avatar wa difficult at first, but then I got used to it.»

«Getting voice was difficult, especially when all the avatars were speaking in the same time.»

«Deciding on the speaking moment was difficult for me and also $I$ had the speakers so long on my ears that I had pains afterwards.»

«Some technical problems about sound.»

How long did it take you to get used to Second Life Platform?

«Not so long.»

«1 or 2 weeks perhaps.»

«After the first lesson, I went to Brazilian beaches, very soon I can say.»

«As I didn't have my own PC and I couldn't follow the lessons regularly it took me some time.»

How real/natural do you think is the SL Environment?

«I felt like in a game at times, »

«Once, I thought that the real people around me are avatars in Second Life, that's how I embraced the environment.»

«Not very different from real, I would say. Sometimes I felt even better as my teacher and friends couldn't see me, and I could speak as relaxed.»

«Looking from real classroom perspective I can say that SL was more enjoyable.

But it was deficient than real interaction sometimes.»

«Very close to real, even more sincere.»

«I felt like in the classroom on my couch while my teacher was lecturing.»

«Being able to get immediate feedback from my teacher, it felt very real.»

What do you think is the effect of SL on your learning?

«Very positive, we do our lesson there, learn new things and we are more comfortable, we speak our minds freely.»

«In this age of technology, it was enjoyable to do our lessons there, $I$ think I learned many new things and I felt confident that I can do better things with the technology.»

«Because you can reach that environment anytime and from anywhere it is definitely positive, especially in individualized learning and for indivual learning pace this could be very effective.»

«Positive, because it allows students to use multiple senses, diverse materials, and to be active and autonomous in the classroom. 》

«With presentations and interactional activities, it is effective and student centered.» 
In what other ways could SL be used?

«It could be used for speaking exams, as students feel more comfortable. Also listening activities»

«Content intorduction in the lessons, theory explanations, information exchange, seminars, courses, meetings and lectures could be done here.»

«For individualized learning.»

«For programs like Erasmus where limited number of students can travel.»

«There could be no limit to the ways of using SL for education, a creative teacher could find a lot of ways to exploit this environment. Especially for practicing speaking with native speakers, intercultural communication, as there are a lot of native speakers on SL»

Off-Campus events could be organized for students.»

\section{CONCLUSION}

According to the findings of the research, it has been observed that moving around the virtual environment is not highly compelling. Also, the majority of the participants have been discovered to be using the environment actively by touching. \%79 of the participants have stated that the interaction is often natural. As there are 3D visuals in the environment student involvement has been achieved by $\% 85$. $\% 64$ of the participants think that experiences in the virtual environment often seem consistent with their real-world experiences. Furthermore, it has been observed that majority of the students are interested in virtual environment and their involvement is pretty high. Although the students encountered some technical problems, they preferred to conduct lessons on Second Life Platform. The rise of interest has been observed through the rise in the participation to the lesson.

Financial Support: This work was supported by Scientific Research Projects Coordination Unit of Istanbul University. Project number is 34106.

Authors' Note: This paper is the extended version of the research summary presented at 8th International Computer \& Instructional Technologies Symposium.

\section{BIODATA and CONTACT ADDRESSES of the AUTHORS}

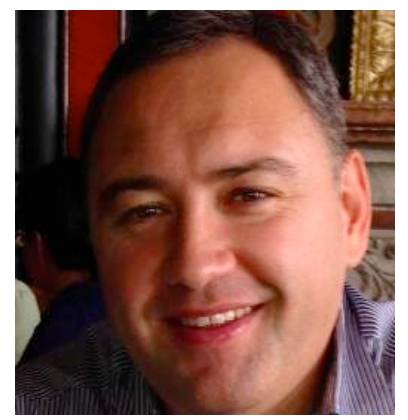

Tuncer CAN completed his PhD at Istanbul University in 2011 on "Foreign Language Learning Strategies". On receiving a Fulbright Scholarship (FLTA) in 2005 he spent a year at Syracuse University, NY, USA, where he taught Turkish via videoconferencing. Besides training pre-service language teachers, he has organized teacher training courses at the Language Center of Istanbul University since 2007. He has also managed and partnered in many projects like "Establishing the Virtual Campus of Istanbul University on Second Life," funded by Istanbul University Research Center and "CAMELOT: CreAting Machinima Empowers Live Online Language Teaching and Learning" funded by European Commission.

\section{Dr.Tuncer CAN}

Istanbul University, Hasan Ali Yücel Faculty of Education

Dept. of English Language and Literature

Mobile: 0 (532) 7311421

Email: tcan@istanbul.edu.tr 


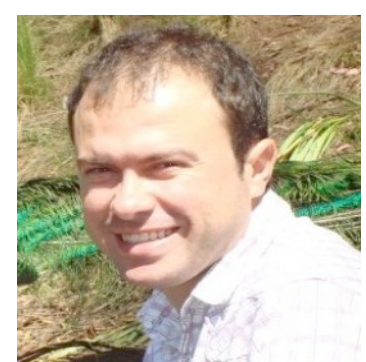

Irfan SIMSEK completed his PhD at Istanbul University in 2013 on "Development of a Web Based Intelligent Examination System According to Measurement and Evaluation Criteria in Education. In 2008 he spent six months at Melbourne University, Melbourne, Australia, where he was invited as a visiting scholar. He has also managed and partnered in many projects like "Establishing the Virtual Campus of Istanbul University on Second Life," funded by Istanbul University Research Center and "CAMELOT: CreAting Machinima Empowers Live Online Language Teaching and Learning"

funded by European Commission.

Dr. Irfan SIMSEK

Istanbul University

Hasan Ali Yücel Faculty of Education

Dept. of Computer Education and Instructional Technologies

Mobile: 0 (532) 3504558

Email: irfan@istanbul.edu.tr

\section{REFERENCES}

Access to Virtual and Action Learning live ONline (www.avalonlearning.eu)

Added Value of teAching in a virTuAl woRId (www.avatarproject.eu)

CreAting Machinima Empowers Live Online Language Teaching and Learning" http://camelotproject.eu

Can, T. (2009). Learning and Teaching Languages Online: A Constructivist Approach. Novitas-ROYAL. 2009, Vol.: 3(1), 60-74.

Chang M. M. (2005). Applying Self-Regulated Learning Strategies in a Web-Based Instruction- An Investigation of Motivation Perception. Computer Assisted Language Learning. Vol. 18, No. 3, July 2005, pp. $217-230$

Coffman, T. \& M. B. Klinger (2008). Utilizing Virtual Worlds in Education: The Implications for Practice. International Journal of Social Sciences. Volume 2 Number 1 s. 29-33

Deutschmann, M., Panichi, L. \& Molka-Danielsson, J. (2009). Designing Oral Participation in Second Life - A Comparative Study of Two Language Proficiency Courses. ReCALL. 21 (2): s. 206-226. doi:10.1017/S0958344009000196

Deutschmann, M. \& L. Panichi (2009). Instructional Design, Teacher Practice and Learner Autonomy. In Molka-Danielsen J. \& M. Deutschmann Learning and Teaching in the Virtual World of Second Life. Trondheim: Tapir akademisk forlag, pp. 27-44.

Deutschmann, M., Steinvall, A. (2012). "Identifying Identity: Using Second Life in the Teaching of Sociolinguistics for the Raising of Gender Awareness" EuroCall Review, 20: 49-53

Edirisingha, P. Nie, M., Pluciennik M. \& R. Young (2009). Socialisation for learning at a distance in a 3-D multi-user virtual environment. British Journal of Educational Technology. Vol 40 No 3 s. 458-479 
Keskitalo, T., Pyykkö, E. \& H. Roukamo (2011). Exploring the meaningful Learning of Students in Second Life. Educational Technology \& Society. 14(1), s.16-26

Kluge, S. \& L. Riley (2008). Teaching in Virtual Worlds: Opportunities and Chanllanges. Issues in Informing Science and Information Technology. Volume 5, s. 127-135

Levy, M. (2009). Technologies in Use for Second Language Learning. The Modern Language Journal. 93 Focus Issue, s. 769-782.

Panichi, L., Deutschmann, M. \& Molka-Danielsen, J. (2010) "Virtual Worlds for Language Learning and Intercultural Exchange: Is it for Real?", in Guth, S. \& Helm F. (2010) (eds.) Telecollaboration 2.0: Language, Literacies and Intercultural Learning in the 21st Century. Peter Lang AG, Bern, pp. 165-195.

Peterson, M. (2010). Learner Participation Patterns and Strategy Use in Second Life: an Exploratory Case Study. ReCALL. 22, s. 273-292

Salmon, G. (2009). The Future for (Second) Life and Learning. British Journal of Educational Technology. Volume 40, No 3, s. 526-538

Sanders R.L. \& L. McKeown (2008). Promoting Reflection through Action Learning in a 3D Virtual World. International Journal of Social Sciences. Volume 2 Number 1, s. 50-55

Ushioda, E. (2011). Language learning motivation, self and identity: current theoretical perspectives, Computer Assisted Language Learning. 24:3, 199-210

Warburton, S. (2009). Second Life in higher education: Assessing potential for and the barriers to deploying virtual worlds in learning and teaching. British Journal of Educational Technology. 40 (3), 414-426. 